\title{
LANGUAGE OF THE ENGLISH-SPEAKING COLOURED CHILD
}

\author{
ROSANNA MILSTEIN, B.A. (Sp.\& H. Therapy) (WITWATERSRAND)
}

105-21 66 Ave., Forest Hills, N. Y. 11375

\begin{abstract}
SUMMARY
The language deficient - language different controversy in the language of the Coloured child was investigated while at the samc time examining Coloured English. The Ss comprised 20 nine-year old English speaking Coloured children, 9 boys and 11 girls. Language samples were obtained through direct questioning according to Halliday's language functions. From these samples, the non-standard language structures used by a significant number of the Ss were isolated, and examined. It was established that the Ss had competence for all these structures except that of relative sentences. Possible reasons for this were postulated. A sub-aim of the study was to compare the ratings of Coloured teachers and a group of speech therapists and university students of non-standard sentences used by the Ss. Based on the findings, several implications for speech therapy were discussed.
\end{abstract}

\section{OPSOMMING}

Die twispunt , taalafwyking" teenoor ,,taalverskil” in die taal van die Kleurlingkind is ondersoek, asook terselfdertyd Kleurlingengels. Dic procfpersone was twintig nege jarige Engelssprekende Klcurlingkinders, 9 seuns en 11 dogters. Taalmonsters is verkry deur direkte vrae volgens Halliday se taalfunksies. Daardie taalstrukture wat nie standaard is nie en wat deur' $n$ betekenisvolle dantal proefpersone gebruik is, is van hierdie monsters geskei en noukeurig ontleed. Daar is vasgestel dat die proefpersone vaardigheid in al hierdie strukture, behalwe in relatiefsinne, getoon het. Moon tlike redes hiervoor word gepostuleer. 'n Sekondêre doel van hierdic studie was om die beoordelings van Kleurlingonderwysers teenoor diè van 'n groep spraakterapeute en universiteitstudente te vergelyk met betrekking tot daardie sinne wat deur die proefpersone gebruik is en nic standaard is nie. Dic implikasies wat die bevindinge vir spraakterapie inhou, word bespreek.

South Africa is both a multi-racial and a multi-lingual society. Any profession concerned with speech and language must take cognizance of this and must include all the subcultures in to its sphere of interest and investigation. This will ensure better understanding, communication and interaction among the members of society. The Coloured People may be viewed as one such subculture, and thus warrant investigation as have done the Negroes and Puerto Ricans. From the point of view of the speech therapist and linguist, the study of such cultures and subcultures offers a wealth of linguistic data which can serve to improve the efficiency of the disciplines.

In studying the English of Coloured children, it is important to bear in mind the standard version of the language. i.e., Standard English (SE). Speakers whose dialects vary from the standard version have been labelled either as being defective or as being linguistically different. ${ }^{2}$ This conflict stems from the 
language deficient - language difference controversy. According to the language deficient view point, the speakers are seen as using an inferior language, a "restricted code" 5,6 together with its concomitants of concreteness, depressed verbal performance, and low conceptualization. ${ }^{5,6,14,28,29,35,38}$ The proponents of the language difference stand point suggest that the language is highly organized, rule governed and systematic, and is in no way inferior. ${ }^{1,9,42}$ The differences that occur are merely in the surface structure. ${ }^{26}$

In this study, when discussing the language used by the Coloured child, the term non-standard will be alternated with "error", both of which will imply a variation, rather than a mistake. From the above it can be seen that in testing, it is important to tap not only what is overt viz. performance, but also what is known and understood about the particular linguistic code viz. competence. This is important as it will determine to an extent the severity of the "error", the approach in therapy, and if in fact, there is to be therapy at all. Competence cannot be directly observed and is thus difficult to assess. ${ }^{3,41}$ Linguistic competence is of little use if the speaker is unable to use his language. This suggests the value of assessing communicative competence ${ }^{\top}$ and the change in language as it is used to fulfill different functions. Halliday ${ }^{15,16}$ discusses several such functions of which three will be investigated in this study. In the representational or textual function, language is used to express propositions about something. This imaginative or ideational model serves to relate the child to his environment in his own way. Through the interactional or interpersonal model, the language is used to establish and maintain social relations. ${ }^{15,16}$ These categories may be theoretical but if they do exist, they are ripe for exploration and may have important implications for the linguist and speech therapist. In particular, they indicate the importance of taking into account the context and meaning when evaluating language.

\section{METHODOLOGY}

\section{AIMS}

The main aim of this study is to investigate certain aspects of the language of the English-speaking Coloured child. This is done with a view to examining the language deficient - language different controversy.

Implicit in this aim are several sub-aims:

To examine the possible change in language as it is used in different language functions. The language functions to be examined are those discussed by Halliday ${ }^{15,16}$ and are a) representational $b$ ) imaginative and c) interactional.

To investigate the possible "concreteness" in the language of the Coloured child. This area is closely allied to the language deficiency hypothesis.

To differentiate the "errors" made by the group as a whole as opposed to those made idiosyncratically by individual children. These may then be characteristics of Coloured English.

To evaluate the in-depth testing of language using both expressive language and structured language tests. 
To compare Coloured speakers' ratings of the children's language with those of a combined speech therapist and university population group. It is important to determine whose judgement to take into account when labelling a child's language "incorrect".

To compare "errors" found with those reported in the literature on other English-speaking minority groups e.g. Puerto Ricans, Negroes.

\section{HYPOTHESIS}

The language of the English-speaking Coloured child is not inferior to SE but is an organised, rule-ordered language. The child is able to express and understand meaning in his environment and is thus not seen as language impaired.

\section{SUBJECTS}

20 Ss were used, 9 boys and 11 girls. The Ss were drawn from two English Medium Coloured Schools in Johannesburg and were all in Std.2. The mean age was 9 years 4 months and the ages ranged from 8 years 5 months to 9 years 8 months. The Ss were selected by the teachers according to several criteria.

1. They had to be approximately between 8 years 6 months and 9 years 6 months. By this age children have acquired all the basic sentence structures and have not yet been influenced by the jargon of the peer group. ${ }^{27}$

2. They had to be of average intelligence and must not have failed at school. The experimenter (E) did not want the factor of intelligence to interfere but at the same time did not want a biased population. For the purposes of this study, scholastic achievement was felt to be an adequate criterion.

3. The Ss had to have no speech, hearing or language problem. The E did not want their performance to be masked by any of the above.

4. The Ss had to come from English-speaking homes and although variables of parental education and socio-economic status could not be controlled for, the above criteria made for a sufficiently homogeneous group.

\section{TESTS USED}

These were designed in two parts:

1. The elicitation of language samples within representational, imaginative and interactional functions of language.

2. Tests of those areas in which the Ss had used non-standard variations of the language.

No standardised tests were used as these were not felt to be appropriate for the sample being tested. The use of standardised tests has led to confusion regarding accurate descriptions of the different language of the culturally different child. ${ }^{40}$ 


\section{TEST I}

$\Lambda$ series of questions was used. These were similar to those used by Lawton. ${ }^{28}$ There were three categories of questions, corresponding to the three language functions being tested. Toys were used to elicit the language which included a goblin, snake, sequence cards, jigsaw puzzles and two telephones. The first questions tapped the representational function of language. Questions such as the S's name, age and address were started with, progressing to a more abstract level e.g. 'Why should people not steal?'

In the imaginative functions, the Ss were required to talk about the rubber goblin and snake. They also had to answer the questions 'What would you do if you had a space ship?' or 'What you do if you were a fairy?', depending on their sex.

For the interactional function, another $\mathrm{S}$ was called in and the two Ss had to have a telephone conversation. They were also given a puzzle which they had to complete together.

The questions were designed to elicit equal amounts of language for each of the three categories. This type of directed, structured language eliciting was felt to be better suited to the population being tested than some of the conventional methods used. $6,29,30,44$

\section{TEST II}

This was designed to assess the competence in those areas of Test I in which the $\mathrm{S} s$ had used different versions of the language. Performance may be affected by certain variables e.g. memory factors, and the interference of physical or psychological processes. ${ }^{32}$ Thus competence cannot be inferred from performance but must be separately investigated.

Only those areas which were "failed" by a significant number of the group were tested. Eight areas were examined and the materials used were sentences, pictures on $17 \times 10 \mathrm{~cm}$ cards - a boy, dog, car, train and lion. In each subtest, there were five items except for subtest 8 , which had seven items.

Subtest 1 - Passives: The Ss had to point to a picture corresponding to a passive sentence. ${ }^{23}$ There was a choice of four pictures so as to reduce the chance factor. Ss were then given an explanation of the passive, focusing on the object, ${ }^{43}$ and had to construct two passive sentences from the two action situations e.g. "The car hits the train" - this is demonstrated "Starting with the words "the train' say what happened to the train". In these, the objects used were such as to yield no semantic cues. ${ }^{37}$ Thus in the above example, either thetrain or the car could have been the subject.

Subtest 2 - Relative Sentences: The Ss had to answer questions about relative sentences e.g. "The girl the boy saw was tall". "Who was tall?" Two types of embedded sentences were used: a) one embedded sentence in the underlying P-marker e.g. the cat that caught the mouse had a long tail $b$ ) one embedded sentence in the underlying P-marker but in the surface structure it is centreembedded e.g. the children the fish saw swam quickly. ${ }^{12}$

The sentences used were controlled for syllable length and here too, as far as possible yielded no semantic cues. ${ }^{37}$ 
Subtest 3 - Prepositions: The Ss had to say whether the sentences were correct or incorrect, this method being referred to as sentence identification. They also had to say whether the picture presented corresponded to a sentence they were given e.g. given a picture of a car having driven into a tree, they had to say whether the sentence "The car drove in the tree" was right or wrong.

Subtest 4 - Pronouns: The Ss had to point to one out of four pictures which corresponded to a sentence. Sentence identification was also used here e.g. I'll buy me a house.

Subtest 5 - Modal:The Ss had to identify sentences as well as construct questions with "can", "will" and "do". Even though the test words were given, it was felt that their competence would be demonstrated if they could use them correctly in a sentence.

Subtest 6 - Incomplete Sentences: Sentence identification was used here.

Subtest 7 -Agreement of $V$ with $N$ of $N P$ and $V P$ : Sentence identification was required here.

Subtest 8 - Tense: The Ss had to identify sentences and had to listen to a short story and fill in the correct word at the end e.g. would/will.

The incorrect sentences used in the tests were either contrived, based on the Ss" "errors", or they were actual sentences used by the Ss.

\section{ADMINISTRATION OF THE TESTS}

TEST I

Each $\mathrm{S}$ was seen individually for about 30 minutes and these interviews we re tape recorded. The interview commenced with the representational function and although questions such as name, age and address yielded language data, they also served to relax the Ss. The questions were asked in the same order for all Ss. The imaginative function was tapped next, followed by the interactional function. Here the responses were both tape recorded and written by the $E$ which served as a double check.

\section{TEST II}

The second session took place one month later and the Ss were seen individually for about 30 minutes. They were told they were going to play different sorts of speech games. The subtests were presented in the same order for all Ss and the instructions were given at the start of each subtest.

\section{ANALYSIS AND STATISTICAL PROCHDURES}

\section{TEST I}

The language samples were transcribed from the tape recorder and a list was compiled of all the "errors" made by the Ss. Context was at all times referred to, following Lee and Canter ${ }^{30}$ From this list, a table was drawn up listing the language classes and the number of "errors" made in each class by each $\mathrm{S}$ in each of the three categories. 
Using the information from the table, a Chi squared test was used to determine which "errors" were made significantly by the group as a whole as opposed to individual "errors". The same test was used to determine whether all three language functions were equally affected for the Ss. The Chi squared test was chosen as the data being dealt with was ordinal and appeared to have directionality..$^{34}$ A further table was compiled, listing the transformations the Ss should have had ${ }^{20,21}$ and those which were present in their language samples. The Chi squared test was used to establish which transformations were omitted by a significant number of the group.

\section{TEST 11}

The Ss were given scores out of 5 for the subtests. The results were tabulated, showing the number of "errors" made by each S for each subtest. The totals were subtracted from 100 to get a score of "incorrect". The Chi squared test was used to determine which of the subtests were failed by a significant number of Ss.

\section{TEACHERS' RATINGS}

A list of 40 sentences used by the Ss which were judged incorrect by the $\mathrm{E}$, and 10 correct control sentences were given to 20 English-speaking Coloured teachers and to 20 speech therapists and university students. The sentences had to be rated as being 'acceptable', 'unacceptable', or 'not sure', if used by a nine-year old. The ratings of the two groups were compared and the Pearson Product Moment correlation coefficient was used to establish the relationship.

\section{RESULTS AND DISCUSSION}

\section{RESULTS OF TEST I}

In analysing the language samples of the $\mathrm{Ss}$, it was established that certain nonstandard versions were used by the group while others were idiosyncratic. This was ascertained using the Chi squared te st where $X_{2}=33,92 ; \mathrm{df}-22 ; p=0,05$. Six language classes were isolated as having contained non-standard structures in the group. Using the value of $\mathrm{E}$ where $\mathrm{E}=$ total number of errors i.e. the extotal number of cases

pected values, it was found that above 11,52 the non-standard structures were used significantly by the group as a whole. The six language classes which fell above this point were "errors" of agreement, tense, prepositions, pronouns, incomplete sentences and modals (Seefigure 1.).

\section{DISCUSSION OF THE SIX "ERRORS"}

Agreement This involved mainly the NP-V relationship e.g. "In the morning, she brush it out". Other "errors" involved the relationship between V and $\mathrm{N}$ of VP and NP auxiliary. This was also found by Ganes ${ }^{13}$ in her study of the written English of Coloured teacher trainees. This has also been noted in Negro dialects where there are no obligatory morphological endings. ${ }^{3,10}$

Tense This structure involved the substitution of one tense for another. The present tense was used for the past, conditional, progressive and future. Future 


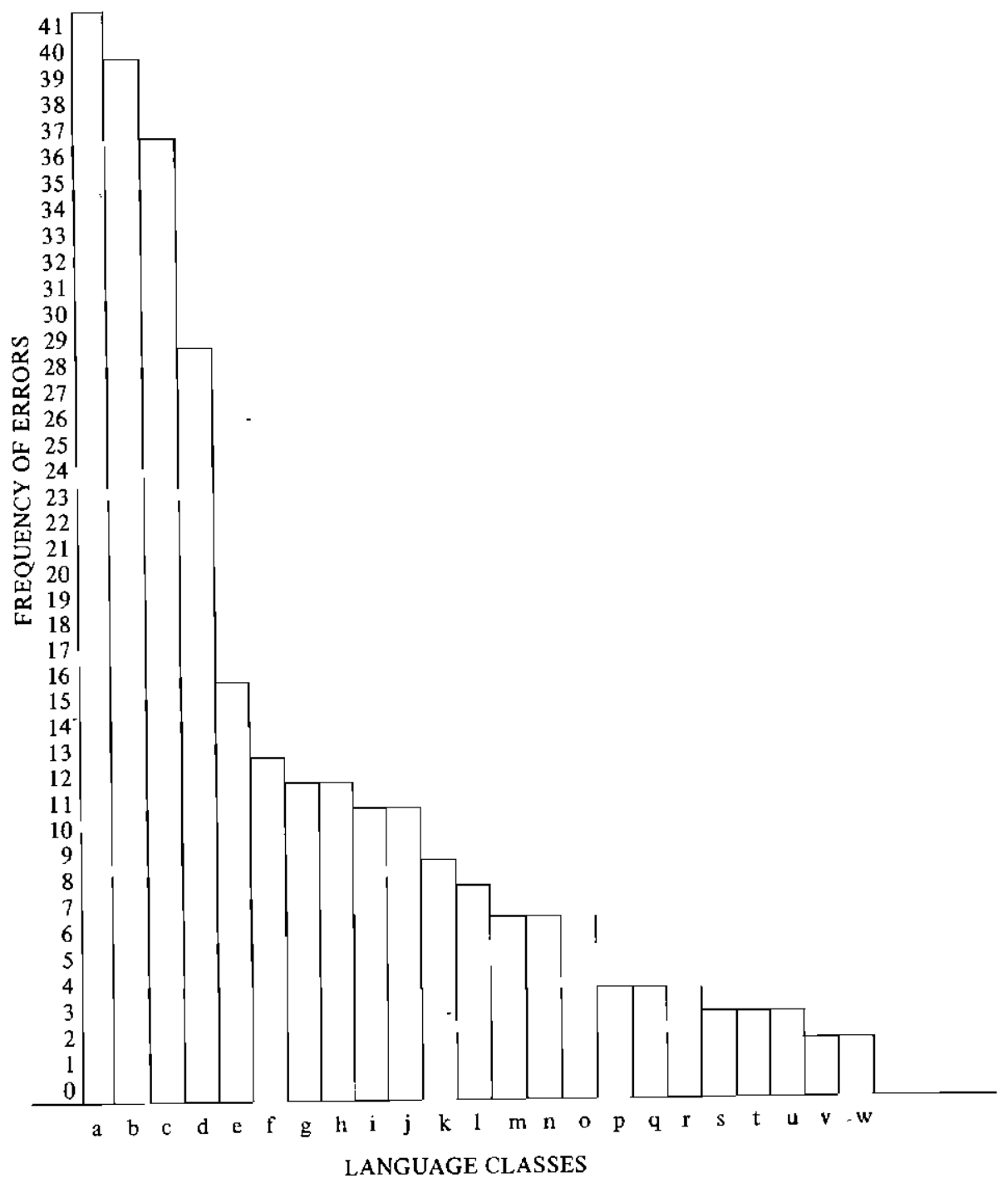

KEY:

$$
\begin{array}{lll}
\mathrm{a}=\text { agreement } & \mathrm{i}=\text { determiner } & \mathrm{q}=\text { plurals } \\
\mathrm{b}=\text { tense } & \mathrm{j}=\text { auxiliary } & \mathrm{r}=\text { participles } \\
\mathrm{c}=\text { preposition } & \mathrm{k}=\text { conjunction } & \mathrm{s}=\text { interrogative reversals } \\
\mathrm{d}=\text { pronouns } & \mathrm{l}=\text { got/my } & \mathrm{t}=\text { "to" } \\
\mathrm{e}=\text { incomplete sentence } & \mathrm{m}=\text { do } & \mathrm{u}=\text { adj/adv } \\
\mathrm{f}=\text { modal } & \mathrm{n}=\text { vocabulary } & \mathrm{v}=\text { double negative } \\
\mathrm{g}=\text { word order } & \mathrm{o}=\text { semantic over elaboration } & \mathrm{w}=\text { miscellaneous } \\
\mathrm{h}=\text { clumsy } & \mathrm{p}=\text { copula } &
\end{array}
$$

Figure 1: Representation of the frequency of errors per Language Class in descending order 
tense was also used for conditional and the past tense was substituted for the future. The main "errors" were the use of future for conditional tense e.g. in response to "What would you do if you had R100?" - "I will put it in the bank". It would appear that this substitution implies an inability to move out of the concrete functioning. It seems that the only areas of operation are those that are definite and tangible viz. past, present and future. Some authors have reported that in Negro dialects, conditionality is represented in word order change but this was not found in the protocols of this study. ${ }^{3}$ With regard to the use of present for past this may be due to the influence of the Afrikaans historical present which is also evident in dialects of SE.,25

Prepositions There were several substitutions found in this language class but it was only those which confused semantic understanding that were considered. These "errors" would be indicative of deficient conceptual relations and thus warrant attention e.g. a frequent substitution was in/at e.g. "I live in 20 North Avenue". This does not impair meaning at all. In contrast, the sentence, "She was thankful for her parents (for giving her the gift)" implies a confusion of "to" and "for" as prepositions and it is this type of factor that necessitates deeper investigation.

Pronouns Three types of non-standard versions were found. The least aberrant was that of omission and this occurred seldom. The use of the accusative pronoun for the reflexive was predominant e.g. "I'll buy me a house." This seemed to occur only in the first person. ${ }^{1}$ A further variation which was considered within this language class was where in a sentence, either the identical NP was not deleted or the pronoun was redundant e.g. "My mother, she goes to town." Adler" has referred to this as "subject expression". Fasold ${ }^{10}$ refers to it as pronominal apposition where a pronoun is used in apposition to the N of NP. $\mathrm{He}$ feels that the length of the modifying material which intervenes between the noun and the pronoun affects the acceptability - the more intervening material, the more acceptable. This may be related to the entry and re-entry of participants in a narrative. ${ }^{10}$

Incomplete Sentences In most cases, the first NP of "it" was absent. Labor ${ }^{24}$ feels that these sentences cannot be considered incorrect as the child must have understood what was said in order to give an appropriate but incomplete response. This makes clear the importance of context in evaluating the language.

Modals These were frequently deleted and occurred mainly in the context of "got" e.g. "See, this man got a gun". 'Got' was not regarded as incorrect unless it was substituted for the main verb of the sentence e.g. got/received,"

The above structures were discussed as they were found to be used by the majority of the group and thus may be seen as characteristic of Coloured English. Non-standard variations were also used by individuals and although they are of interest, they cannot be discussed here.

Language Functions It was found that the three language categories were differentially affected by the "errors". Using the Chi squared test, where $\mathrm{X}_{2}=$ 5,$99 ; \mathrm{df}=2 ; \mathrm{p}=0,05$ it was found that representational language had a significant number of non-standard structures $X_{2}=12,08$. Both imaginative and interactional language were not affected by the "errors", imaginative language 
having $X_{2}=0,005$ and interactional language $X_{2}=12,57$. It can be seen that interactional language was not affected significantly. These results should however be viewed with reservation as although the test was designed to elicit equal amounts of language for each category, it is possible that unequal amounts were obtained, making the results less comparable.

Transformations that Were Omitted. The protocols were judged against a format of transformations passive, negatives, relative sentences, adjectives, pronouns, prepositions and adverbs. It was found that the Ss did not use passives, relative sentences and adverbs significantly as a group. This was established using the Chi squared test where $\mathrm{X}_{2}=3,84 ; \mathrm{df}=1 ; \mathrm{p}=0,05$. Passives and relative clauses were included in Test II but adverbs were omitted as it was felt that the area was too vast to be included in the confines of the study.

\section{RESULTS OF TFST II}

Relative Sentences. This subtest was failed by the group as a whole. This was ascertained through the Chi squared test where $\mathrm{X}_{2}=3,84 ; \mathrm{df}=1 ; \mathrm{p}=0,05$. There thus appears to be a defect in the competence for relative sentences. The Ss did not, as suggested by Strohner ${ }^{43}$ rely on syntactic information but rather on strategies. A possible explanation for this may be the age of the Ss. It would be of interest to test for the evidence of this structure in an older child.

Passives. Although these were not used spontaneously, the Ss appeared to have the competence as they were able to understand and generate passive sentences. This may be due to the fact that the passive is learned late and memory may be involved in its production. In addition production lags behind comprehension and this may have been operative here too. ${ }^{12}$

Modals. This was well coped with, suggesting the "errors" made in Test I were merely performance "errors" and were brought about by other factors e.g. phonological rules, rather than by a lack of competence in these areas.

Tense. Here too Ss coped well, suggesting that the "errors" were purely on a performance level. However it was felt that there was no semantic differentiation between e.g. should/shall. When asked the difference between these two words, some Ss said there was no difference, others stating the difference by giving two sentences without going into the meaning. It is difficult to draw any conclusions from this but a possible explanation may be an inability to express subtle differences between the words, a difficulty manifested by all nine-year olds. A control group would have been useful here to evaluate whether this difficulty was culture specific or age group specific.

Prepositions. The "errors" seemed to be purely on a performance level and the Ss appeared to have the conceptual meanings of the prepositions used incorrectly.

Pronouns. These were well managed indicating that the Ss had the competence for these but broke down on a performance level.

Incomplete Sentences. As mentioned earlier, these were not deficient in meaning, and the fact that the competence is there is borne out by the fact that Ss were able to recognise and correct these sentences. 
Agreement. There appeared to be the competence for agreement between NP.V and $\mathrm{V}$ and $\mathrm{N}$ of NP but the breakdown is on a performance level due to extraneous variables e.g. phonological rules.

Thus all errors were surface structure "errors" except for relative sentences. (See Table 1.)

\begin{tabular}{|l|c|c|c|}
\hline Language Classes & $\begin{array}{c}\text { Total } \\
\text { Correct }\end{array}$ & $\begin{array}{r}\text { Total } \\
\text { Incorrect }\end{array}$ & $\begin{array}{c}\mathrm{X}_{2}=3,84 \\
\mathrm{df}=1, \mathrm{p}=5 \%\end{array}$ \\
\cline { 1 - 2 } Passives & 91 & 9 & 1,26 \\
\hline Relative sentences & 59 & 41 & 5,93 \\
\hline Prepositions & 87 & 13 &, 46 \\
\hline Pronouns & 78 & 22 &, 1 \\
\hline Modals & 95 & -5 & 2,46 \\
\hline Incomplete sentences & 85 & 15 &, 21 \\
\cline { 1 - 1 } Agreement & 83 & 17 &, 05 \\
\hline Tense & 69,3 & 30,7 & 1,66 \\
\hline
\end{tabular}

TABLE I. SUMMARY OF RESULTS FOR COMPETENCE SUB-TEST (TEST II)

Teacher Rating. As this was designed to examine the similarity or difference of the two groups' ratings, correlations were established for each of the three ratings. Using the Pearson Product Moment Correlation, correlations of ,89,83 and, 59 were established for the three ratings respectively. This means that there was a high level of agreement between the two groups for sentences that were clearly 'acceptable' or 'unacceptable'. However, there is some disparity between the two groups on their ratings of sentences of which they were not sure. This may be because the group of Coloured teachers were more definite about their decisions, perhaps because they were familiar with both the language used in the sample sentences and the nine-year old group. The other group found it difficult to visualize how a nine-year old speaks and were thus 'not sure' more often.

\section{DISCUSSION}

Concreteness of Language. The language of the Ss and their responses to the questions were felt to have been fairly concrete and situation bound. This feature was noted in various forms. It could be seen in the Ss' relating of their 
experiences, the story telling and in the syntax where frequently, structures implying concrete notions were used e.g. fut ure for conditional tense. However, even though these factors may have been evident, it is incorrect to attribute them to the language of the Coloured child. The language of nine-year old SE speakers has not been examined and thus no statements, other than tentative ones, can be made about the language of the Coloured child. Furthermore, the concreteness of language must not necessarily be pinned to the speaker but rather to the factors operative at the time of testing. Most obvious here is the influence of the testing situation on the language of the Ss.

Variables in Testing Situation. It is inevitable that the race of $\mathrm{E}$, as well as her age and authority, had an effect on the verbal output. ${ }^{40}$ " ... the power relationship in a one-to-one confrontation between adult and child are too asymmetrical." 24 This may have rendered the language more formal and possibly more concrete. It has been found that the greater the difference in status between the tester and $\mathrm{S}$, the more the $\mathrm{S}$ strives to use standard forms. ${ }^{11,26,40}$ Had a different tester been used, perhaps of the same race, maybe even the same or closer age group, the Ss may have given a truer representation of Coloured English, along with even more non-standard structures. In addition, the poor performance may be due to a lack of understanding of the instructions. Weener ${ }^{40}$ says that the ability to process natural language is directly related to the degree to which phonetic, syntactic and semantic features of a message match those same features of the speaker's own dialect.

Influence of $A$ frikaans. There is yet another possible explanation for the nonstandard structures in Coloured English - the influence of another language, in this instance, Afrikaans. Although the Ss were drawn from Englsih-speaking homes and schools Afrikaans is the dominant language of the Coloured population (one English speaker to eight Afrikaans speakers ${ }^{33}$ ). All the Ss have been in contact with Afrikaans speakers, speaking either Afrikaans or non-standard English. The influence of one language on another has been defined differently by various authors. ${ }^{8,17,19}$ Features of the one language impinge on the other, and the interference is said to be in the language performance. ${ }^{4}$ The more similar the two languages, the more interference there is. ${ }^{39}$ This would seem to apply to the case in point, as the English used by Afrikaans speakers is closer to that used by English-speaking Coloureds than a completely different language e.g. Afrikaans.

Additional Aspects. A further observation that was made based on the protocols of the Ss was a frequent use of sentences beginning with 'and', 'but', 'then' and 'because'. The commencement of sentences with 'and' and 'but', also found by Templin ${ }^{44}$ may be viewed as misuse of conjunctions. It is possible that the Ss did not have the concepts and semantic meanings of these words and thus used them at the beginning of sentences. Two factors invalidate the above statement. The first is that both these words were used correctly in the language of the Ss, implying that the competence for their meanings and uses does exist. Secondly, these words are frequently used by speakers of SE, possibly those of a lower socio-economic status. On heuristic observation, this has frequently been noted in the language of all races, and thus must be judged with reservation. On the other hand, the frequency of the usage of these words 
may be illustrative of a deficiency ${ }^{31}$ and may be indicative of a limited vocabulary. It may be a further manifestation of the stilted, concrete nature of language which, as mentioned above, may have been partially caused by the test situation. The frequent use of 'jus' within the sentences is common in less formal speech, but may also be indicative of loss for words: Once again, judgement here must be made with reservation.

\section{CONCLUSIONS}

From the above, there are several conclusions and implications which can be drawn, all which aid in dealing with the Coloured child, be it in the form of speech therapist, teacher or research worker. Broadly speaking, it would seem that the language of the English-speaking Coloured child cannot be seen as inferior or deficient. It appears to serve adequately the communicative needs of the child, allows him to express himself and meaning in his environment and can be said to be deficient no more than any one language can be said to be inferior to another. In contrast, Coloured English may be viewed as a different language which is how Labor ${ }^{24}$ refers to the language of lower class speakers. Yet, whatever the label given, there still exists an intercultural communication problem, especially when adjudged by speakers of SE.

\section{IMPLICATIONS FOR SPEECH THERAPY}

There are specific implications for both testing in therapy and for the actual administration of therapy.

Testing. It seems, as mentioned earlier, that the method used to tap the Ss' language is appropriate to the Coloured population. Although no spontaneous speech was directly attained, direct probing elicited sufficient language for linguistic analysis. This method of direct questioning is felt to be beneficial in a test situation where the $S$ is not outgoing but even so, it must be tactfully handled in order not to intimidate the child. In the language samples obtained it was frequently difficult to distinguish between what was directly elicited and what was spontaneously given by the child. This would further seem to indicate the comparability and efficacy of using a structured means for getting a language sample. In addition, the linguistic content should be adapted to the child's system, thus ensuring that he understands what is required of him. ${ }^{36}$ Further, in evaluating responses, context must be taken into account. ${ }^{19}$ This is particularly important when dealing with a culture different from that of the therapist. The therapist can no longer take for granted meanings of words used by children under test and must actively investigate the environment. This makes clear the shortfalls of using traditional TG methods for analysing and evaluating the language of Coloured children. At all times semantics must be referred to, the relations of the linguistic occurrences to the rest of the child's world, and only in this way will their language be interpreted correctly and fairly. It can also be seen that it is important to probe deeper than performance as it is very often influenced by extraneous variables. Thus an attempt must be made to tap competence as well as performance.

Therapy. The conclusion that the language of the Coloured child is different, as opposed to deficient, throws a different light on therapy. Several suggestions 
have been made regarding this issue. It has been suggested that because the language is not deficient, it should be the avenue through which the child is taught the new or target language. ${ }^{4}$ The mother tongue which is used initially by the child should be used as much as possible in teaching the new language as this will promote better understanding, more carry-over between home and therapy, and the break from home will be minimized. ${ }^{8}$

The acceptance by the therapist of the child's language is of utmost importance ${ }^{22}$ and the therapist cannot be glib in admonishing a child's use of language and proclaiming it incorrect. This may result in the child's seeing himself as illogi$\mathrm{cal}$ and incorrect, and the psychological factors involved may be permanently damaging. The child will react to his failure and what may have originally been a language problem may grow into a learning and emotional one. ${ }^{24}$

Yet another implication for the speech therapist is that she must not only accept the language of the child but must understand it and if necessary, endeavour to use it."18 "Such use, should among other gains, foster better social acceptance of the clinician by the child." 2 This is important as the therapeutic relationship plays a large role. In addition, an understanding ot the child's culture, his needs and values ${ }^{14}$ and the dynamics operative in therapy ${ }^{5}$ are expedient in the successful dealing with the child, especially if he belongs to a different subculture to that of the therapist.

In actually teaching structures, the therapist must determine the cause of the "errors". If the child is lacking in competence, therapy will be geared to its training. If however the "error" is on a performance level only, the child will need less instruction and his attention may merely be drawn to the standard production. If the "error" is related to the factors in his knowledge e.g. phonological system, there is little reason to teach the child the structure without taking into account its determinants.

The findings with regard to the differential occurrence of non-standard structures within different language functions are also of interest to the speech therapist. This may give an indication as to which language functions should be started with and which may be used to facilitate carryover.

The high correlation that existed between the ratings of the children's sentences by the teachers and the group of speech therapists and university students indicates that to an extent, an incorrect structure is universally incorrect, regardless of the culture or status of the judge. For the speech therapist, it means that the opinions and judgements of the teachers can be relied on. This does not mean that no further investigation need be done but does imply that the teachers of the children are reliable referrants.

In the area of Coloured language, the field is wide open to investigation.

Studies controlling many of the independent variables may lead to the isolation of factors pertinent to and influential in the understanding, description or treatment of children. The variation of language within the group as a whole may be of interest e.g. the change of language with race, sex, status and age. It would be of interest to see if at any age, competence for relative sentences is acquired.

These investigations would surely have invaluable implications for the speech 
therapist. Just as it was of interest to see what the Coloured teachers rated correct and incorrect, so would it be enlightening to determine what the Coloured children themselves term correct or incorrect. Do these evaluations differ with status in the community? Above all, norms are required for age groups, sex, status, all of which may validate the work with these children or refute therapy on the grounds that the reference points have been unrealistic.

\section{REFERENCES}

1. Adler, S. (1971): Dialectal Differences: Professional and Clinical Implications. J. Speech Hear. Dis. 36(1), 90-100.

2. Adler, S. (1973): Social Class Bases of Language: A Re-examination of Socioeconomic, Sociopsychological and Sociolinguistic Factors. Asha (1) 3-9.

3. Baratz, J.C. (1969): Language and Cognitive Assessment of Negro Children: Assumptions and Research Need. Asha 11 (2) 87-92.

4. Baratz, J.C. (1970): Should Black Children Learn White Dialect? Asha 12 (9) 415417.

5. Bernstein, B. (1959): A Public Language; Some Sociological Implications of a Linguistic Form. Brit J. Sociol. 10, 311-326.

6. Bernstein, B. (1962): Social Class, Linguistic Codes and Grammatical Elements. Lang. Speech 5, 221-240.

7. Cazden, C.B.(1972): Child Language and Education. Holt, Rinehart and Winston, Inc.

8. Crothers, E. and Suppes, P. (1967): Experiment in Second-Language Learning. Academic Press Inc.

9. Destefant, J.S. (1973): Black English. In Language, Society and Education: A Profile of Black English. Destefano, J.S. (Ed.) Charles A. Jones Publishing Company.

10. Fasold, R.W. and Wolfram, W. (1973): Some Linguistic Features of Negro Dialect. In Language, Society and Education: A Profile of Black English. Destefano, J.S. (Ed.) Charles A. Jones Publishing Company.

11. Fishman, J. (1964): Guidelines for Testing Minority Group Children. J. Soc. Issues 20 (2) 129-145.

12. Gaer, E.P. (1967): Children's Understanding and Production of Sentences. J. Verb. Learn. Verb. Behav. 8, 289-294.

13. Ganes, G. (1967): An Analysis of Errors in the Written English of 28 Coloured Teacher-Trainees. Unpublished Research Report, Department of Phonetics and Linguistics, University of Witwatersrand, Johannesburg.

14. Ginsberg, H. (1972): The Myth of the Deprived Child. Prentice Hall Inc.

15. Halliday, M.A.K. (1973): Explorations in the Functions of Language. Edward Arnold Ltd, London.

16. Halliday, M.A.K. (1970): Language Structure and Language Function. In New Horizons in Linguistics, Lyons, J. (Ed.) Penguin Books Ltd.

17. Halliday, M.A.K. (1968): The Users and Uses of Language. In Readings in the Sociology of Language, Fishman, J.A. (Ed.). Mouton and-Co Printers, The Hague.

18. Honeyford, R. (1972): Class Talk. Brit. J. Dis Commun. 7(2) 206-211.

19. Hymes, D. (1971): Competence and Performance in Linguistic Theory. 
In Language Acquisition: Models and Methods, Huxley, R. and Ingram, E. (Eds.). Academic Press Inc. London.

20. Jacobs, R.A. and Rosenbaum, P.S. (1967): Grammar 1. Ginn and Company, U.S.

21. Jacobs, R.A. and Rosenbaum, P.S. (1967): Grammar 2. Ginn and Company, U.S.

22. Johnson, K.R. (1970): Blacks. In Reading for the Disadvantaged: Problems of Linguistically Different Learners, Horn, T.R. (Ed.) Harcourt, Brace and World, Inc.

23. Kessel, F.S. (1970): The Role of Syntax in Children's Comprehension from Ages 6-12. Monogr. Soc. Res. Child. Developm. 35(6).

24. Labor, W. (1973): The Logic of Nonstandard English. In Language, Society and Education: A Profile of Black English, Destefano, J.S. (Ed.). Charles A. Jones Publishing Company, U.S.

25. Labor, W. and Cohen, P. (1973): Some Suggestions for Teaching Standard English to Speakers of Nonstandard Urban Dialects. In Language, Society and Education: A Profile of Black English, Destefano, J.S. (Ed.). Charles A. Jones Publishing Company, U.S.

26. Labor, W. and Cohen, P. (1973): Systematic Relations of Standard and Nonst andard Rules in the Grammar of Negro Speakers. In Language, Society and Education: A Profile of Black English, Destefano, J.S. (Ed.). Charles A. Jones Publishing Company, U.S.

27. Lanham, L.W. (1975): Personal Communication. Professor, Department of Phonetics and Linguistics, University of the Witwatersrand, Johannesburg.

28. Lawton, D. (1969): Social Class, Language and Education, Routledge and Kegan Paul Ltd. London.

29. Lawton, D. (1964): Social Class Language Differences in Group Discussions. Lang. Speech 7(3) 183-204.

30. Lee, L.L. and Canter, S.M. (1971): Development Sentence Scoring: A Clinical Procedure for Estimating Syntactic Development in Children's Spontaneous Speech. J. Speech Hear. Dis. 36(3) 315-340.

31. Leonard, L.B. (1972): What is Deviant Language? J. Speech Hear. Dis. 37(4) 427446.

32. Lyons, J. (1970): Chomsky. Fontana Modern Masters, London.

33. Mainwaring, K. (1962): The Contribution of the Coloured People to Culture in South Africa. In Understanding One Another. S.A. Institute of Race Relations.

34. McCall, R.B. (1970): Fundamental Statistics for Psychology. Harcourt, Brace and World, Inc. U.S.

35. McDavid, R.I. (Jnr) (1966): Dialectal Differences and Social Differences in an Urban Society. In Sociolinguistics, Bright, W. (Ed.) Mouton and Co. Publishers, The Hague.

36. Patterson, S. (1953): Colour and Culture in South Africa. Routledge and Kekan Paul Limited, London.

37. Penn, C. (1972): A Linguistic Approach to the Detection of Minimal Language Dysfunction in Aphasia. Unpublished Research Report, Department of Speech Pathology and Audiology, University of Witwatersrand, Johannesburg. 
38. Riessman, F. (1962): The Culturally Deprived Child. Harper and Brothers Publishers, New York.

39. Saville, M.R. (1970): Language and the Disadvantaged. In Reading for the Disadvantaged: Problems of Linguistically Different Learners, Horn, T.R. (Ed.) Harcourt, Brace and World, Inc. U.S.

40. Severson, R.A. and Guest, K.E. (1972): Toward the Standardised Assessment of the Language of Disadvantaged Children. In Language and Poverty: Perspectives of a Theme, Williams, F. (Ed.) Markham Publishing Company, Chicago.

41. Shriner, T.H. and Miner, L. (1968): Morphological Structures in the Language of Disadvantaged and Advantaged Children. In J. Speech Hear. Res. l1(3) $605-610$.

42. Shuy, R.W. (1972): The Sociolinguist and Urban Language Problems. In Language and Poverty: Perspectives on a Theme, Williams, F. (Ed.) Markham Publishing Company, Chicago.

43. Strohner, H. and Nelson, K.E. (1974): The Young Child's Development of Sentence Comprehension: Influence of Event Probability, Nonverbal Context, Syntactic Form and Strategies. Child Developm. 45(3) 567-576.

44. Templin, M.C. (1957): Certain Language Skills in Children. University of Minnesota Press, Minneapolis.

45. (1968): The Use of Vernacular Languages in Education: The Report of the UNESCO Meeting of Specialists, 1951. In Readings in the Sociology of Language, Fishman, J.A. (Ed.) Mouton and Co. Printers, The Hague.

\section{BOOKS ON SPEECH AND HEARING}

\begin{tabular}{|c|c|}
\hline JOHANNESBURG: & $\begin{array}{l}\text { Campus Bookshop } 34 \text { Bertha St } \\
\text { Braamfontein } 724-8541\end{array}$ \\
\hline & $\begin{array}{l}\text { Westdene Services } 76 \text { King George St } \\
\text { Hospital Hill } 724-9345\end{array}$ \\
\hline \multirow[t]{2}{*}{ DURBAN: } & $\begin{array}{l}\text { Logan's University Bookshop } \\
229 \text { Francois Road Durban } \\
\text { Telephone } 354111\end{array}$ \\
\hline & $\begin{array}{l}\text { Westdene Services } 604 \text { Eagle BIdg } \\
\text { Murchies Passage West Street } \\
\text { Telephone } 24403\end{array}$ \\
\hline CAPE TOWN: & $\begin{array}{l}\text { Westdene Services Sanso Centre } \\
\text { Adderley Street Cape Town } \\
\text { Telephone } 411061\end{array}$ \\
\hline PRETORIA: & $\begin{array}{l}\text { Westdene Services Shop } 35 \\
\text { Ground Floor Nedbank Plaza } \\
\text { Beatrix Street Arcadia } \\
\text { Telephone } 26336\end{array}$ \\
\hline PIETERMARITZBURG: & $\begin{array}{l}\text { Logan's University Bookshop } \\
\text { Nedbanik Plaza Scottsville } \\
\text { Telephone } 41580 / 41588 / 41589\end{array}$ \\
\hline
\end{tabular}

\section{LITERARY SERVICES (PTY) LTD}




\section{Medical City Elotf cor. Jeppe Street Johannesburg, Transvaal \\ Telephone 23-6685 \\ P.O. Box 52041 \\ SAXONWOLD 2132}

\section{HEARING AIDS.}

\section{WE SPECIALIZE IN}

The supply and fitting of Hearing Aids for all hearing losses, especially for

Nerve deafness

Recruitment

Bone conduction cases.

\section{CROSS AIDS:}

$$
\text { CROS - BICROS - MULTICROS - etc. }
$$

\section{BONE CONDUCTION AIDS for}

Body, Earlevel, Glasses (speciality by Viennatone)

\section{BINAURAL FITTINGS}

We import and stock :-

Viennatone, Qualitone, Microson, Phonak hearing aids.

MOULDS:

$$
\text { Soft, hard, skeleton, vented, occluded etc. }
$$

\section{REPAIRS:}

All aids supplied with a scientific performance report after repair.

SPECIAL PRICES for Dealers and Institutions.

\section{ACCESSORIES:}

Teacher - pupil, parent - child, individual Audiotrainers, very reasonably priced. Group Audio Trainers.

TV - Wireless infrared Transistor Receiver sets made by SENNHEISER. Audiometers: Screening, Diagnostic, Research, ERA and Electrocochleography C.O.R. and Peep Show.

Impedance bridges.

Manufacturers of Sound proof booth and sound proof rooms.

Hearing Aid testing set by "Fonix" U.S.A.

Phonak noise generator with different frequencies, pure tone and warble tone, for everyday's use.

We repair and calibrate Audiometers.

Sound level meters, calibrators.

Industrial noise consultants. 